Article

\title{
Antioxidant and Anti- $\alpha$-Glucosidase Activities of Various Solvent Extracts and Major Bioactive Components from the Fruits of Crataegus pinnatifida
}

\author{
Yen-Ting Lin ${ }^{1}$, Hsiang-Ru Lin ${ }^{2}$, Chang-Syun Yang ${ }^{1}$, Chia-Ching Liaw ${ }^{3,4}{ }^{\mathbb{D}}$, Ping-Jyun Sung ${ }^{5} \mathbb{D}$, \\ Yueh-Hsiung Kuo ${ }^{6,7,8} \mathbb{D}$, Ming-Jen Cheng ${ }^{9, *} \mathbb{D}$ and Jih-Jung Chen $1,6, *(\mathbb{D})$
}

\section{check for}

updates

Citation: Lin, Y.-T.; Lin, H.-R.; Yang, C.-S.; Liaw, C.-C.; Sung, P.-J.; Kuo,

Y.-H.; Cheng, M.-J.; Chen, J.-J.

Antioxidant and Anti- $\alpha$-Glucosidase Activities of Various Solvent Extracts and Major Bioactive Components from the Fruits of Crataegus

pinnatifida. Antioxidants 2022, 11, 320. https://doi.org/10.3390/ antiox 11020320

Academic Editors: Dimitrios Stagos

Received: 22 December 2021

Accepted: 1 February 2022

Published: 6 February 2022

Publisher's Note: MDPI stays neutral with regard to jurisdictional claims in published maps and institutional affiliations.

Copyright: (C) 2022 by the authors. Licensee MDPI, Basel, Switzerland. This article is an open access article distributed under the terms and conditions of the Creative Commons Attribution (CC BY) license (https:// creativecommons.org/licenses/by/ $4.0 /)$.
1 Department of Pharmacy, School of Pharmaceutical Sciences, National Yang Ming Chiao Tung University, Taipei 112, Taiwan; yt197.ps09@nycu.edu.tw (Y.-T.L.); tim0619@nycu.edu.tw (C.-S.Y.)

2 Department of Chemistry, College of Science, National Kaohsiung Normal University, Kaohsiung 824, Taiwan; t3136@nknu.edu.tw

3 National Research Institute of Chinese Medicine, Ministry of Health and Welfare, Taipei 112, Taiwan; liawcc@nricm.edu.tw

4 Department of Biochemical Science and Technology, National Chiayi University, Chiayi 600, Taiwan

5 National Museum of Marine Biology and Aquarium, Pingtung 944, Taiwan; pjsung@nmmba.gov.tw

6 Department of Medical Research, China Medical University Hospital, China Medical University, Taichung 404, Taiwan; kuoyh@mail.cmu.edu.tw

7 Department of Biotechnology, Asia University, Taichung 413, Taiwan

8 Department of Chinese Pharmaceutical Sciences and Chinese Medicine Resources, College of Pharmacy, China Medical University, Taichung 404, Taiwan

9 Bioresource Collection and Research Center (BCRC), Food Industry Research and Development Institute (FIRDI), Hsinchu 300, Taiwan

* Correspondence: chengfirdi@gmail.com (M.-J.C.); jjungchen@nycu.edu.tw (J.-J.C.); Tel.: +886-2-2826-7195 (J.-J.C.); Fax: +886-2-2823-2940 (J.-J.C.)

Abstract: Crataegus pinnatifida is used to treat various diseases, including indigestion, congestive heart failure, hypertension, atherosclerosis, and myocardial dysfunction. We evaluated antioxidant and anti$\alpha$-glucosidase activities of various solvent extracts and major bioactive components from the fruit of $C$. pinnatifida. Ethyl acetate extracts showed potent antioxidant activities with $\mathrm{IC}_{50}$ values of $23.26 \pm 1.97$ and $50.73 \pm 8.03 \mu \mathrm{g} / \mathrm{mL}$, respectively, in DPPH and ABTS radical scavenging assays. Acetone extract exhibited significant anti- $\alpha$-glucosidase activity with $\mathrm{IC}_{50}$ values of $42.35 \pm 2.48 \mu \mathrm{g} / \mathrm{mL}$. HPLC analysis was used to examine and compare the content of active components in various solvent extracts. We isolated four active compounds and evaluated their antioxidant and anti- $\alpha$-glucosidase properties. Among the isolated compounds, chlorogenic acid and hyperoside showed potential antioxidant activities in ABTS and superoxide radical scavenging assays. Moreover, hyperoside also displayed stronger anti- $\alpha$-glucosidase activity than other isolates. The molecular docking model and the hydrophilic interactive mode of anti- $\alpha$-glucosidase assay revealed that hyperoside might have a higher antagonistic effect than positive control acarbose. The present study suggests that C. pinnatifida and its active extracts and components are worth further investigation and might be expectantly developed as the candidates for the treatment or prevention of oxidative stress-related diseases and hyperglycemia.

Keywords: Crataegus pinnatifida; various solvent extracts; active components; antioxidant activity; anti- $\alpha$-glucosidase activity; molecular docking

\section{Introduction}

Free radicals are generated from normal biochemical reactions in the body and increase oxidative stress and probably damage biological molecules such as lipids, proteins, and DNA [1]. Free radicals are associated with cancer, atherosclerosis, aging, inflammation, ischemic heart disease, diabetes, and neurodegenerative disorders [2]. To diminish the 
oxidative stress of free radicals, many synthetic antioxidants were used in industries to delay or inhibit cellular damage mainly through their free radical scavenging property [3]. Natural antioxidants from plant products received attention since they may be safer and more effective in reducing reactive oxygen species (ROS) levels compared to synthetic single dietary antioxidants [4].

Phenolic compounds are free radical scavengers (FRS) that delay or repress the initiation step or hinder the propagation step of lipid oxidation [5]. The antioxidant mechanism of phenolic compounds is that the aromatic ring donates $\mathrm{H}^{+}$to the free radicals during oxidation and become a radical themselves. These radical intermediates are stabilized by the resonance delocalization of the electron within the aromatic ring [6]. For the excellent antioxidant capacity of phenolic compounds, they are regarded as natural antioxidants.

Oxidative DNA damage links pathogenically to multiple aging-regarding degenerative diseases such as cancer, coronary heart disease, and diabetes [7]. Growing evidence of both experimental and clinical studies suggests that there is an affinity between hyperglycemia, oxidative stress, and diabetic complications [8]. ROSs result in defective insulin gene expression and insulin secretion as well as increased apoptosis to increase the risk of DM [9].

$\alpha$-Glucosidase is an essential enzyme in human carbohydrate metabolism. Many studies have affirmed the association between $\alpha$-glucosidase inhibitors and blood glucose regulation in type II diabetic patients [10]. $\alpha$-Glucosidase enzymes are in the brush-border surface membrane of intestinal cells and catalyze the hydrolysis of the $\alpha$-glycosidic bond of oligosaccharides to release monosaccharide units from dietary sources. Thus, $\alpha$-glucosidase inhibitors can delay glucose assimilation and decrease postprandial plasma glucose levels [11]. $\alpha$-Glucosidase inhibitors such as voglibose, acarbose, and miglitol can control postprandial hyperglycemia in DM patients. Nevertheless, these drugs demonstrate adverse side effects, including hepatotoxicity, weight gain, and cardiovascular problems [10].

Crataegus pinnatifida is a traditional Chinese medicinal (TCM) herb that is classified as the Rosaceae family and is widely distributed in the north of China [12]. Fruits of C. pinnatifida can be used as medicine and food for its safety [13]. In traditional Chinese medicine, C. pinnatifida is used in prescriptions to treat indigestion with epigastric distention, abdominal pain, diarrhea, hyperlipidemia, amenorrhea, and hypertension [14]. Previous studies have demonstrated that C. pinnatifida also possesses various biological activities, including lipid regulating, anti-atherosclerosis, antihypertensive, antibacterial, antiviral, anticancer, immunoregulating, anti-inflammatory, and antioxidant activities [12,15-18]. In the present study, we investigated the antioxidant and anti- $\alpha$-glucosidase effects of different solvent extracts and major bioactive components from the fruits of $C$. pinnatifida. Moreover, we conducted molecular docking between $\alpha$-glucosidase and hyperoside with the most potent anti- $\alpha$-glucosidase activity. In addition, the amounts of isolated compounds were quantified by HPLC analysis. The antioxidant and anti- $\alpha$-glucosidase effects of isolated components were also evaluated.

\section{Materials and Methods}

\subsection{Chemicals and Reagent}

Ascorbic acid, 2,2'-azino-bis(3-ethylbenzothiazoline-6-sulfonic acid) (ABTS), $\alpha$-glucosidase, ethylenediaminetetraacetic acid (EDTA), gallic acid, Folin-ciocalteau's reagent, hydrogen peroxide solution, Trolox, and 2,4,6-Tris(2-pyridyl)-s-triazine (TPTZ) were purchased from Sigma-Aldrich (St. Louis, MO, USA). Ferric chloride $\left(\mathrm{FeCl}_{3}\right)$ and $p$-nitrophenyl- $\alpha$-D-glucopyranoside ( $p$-NPG) were obtained from Alfa Aesar (Lancashire, UK). Disodium hydrogenphosphate, potassium peroxodisulfate, sodium carbonate, and potassium dihydrogenphosphate were acquired from the SHOWA Chemical Co. Ltd. (Chuo-ku, Japan). 2,2-diphenyl-1-(2,4,6-trinitrophenyl)hydrazyl (DPPH), deoxyribose, nitroblue tetrazolium (NBT), phenazine methosulphate (PMS), and 2-thiobarbituric acid (TBA) were supplied by Tokyo Chemical Industry Co., Ltd. (Tokyo, Japan). Butyl hydroxytoluene (BHT), acarbose, nicotinamide adenine dinucleotide (NADH), sodium acetate, trichloroacetic acid (TCA), and potassium acetate were acquired from Acros Organics (Geel, Belgium). Acetic 
acid was supplied by Avantor Performance Materials, LLC (Radnor, PA, USA). Sodium hydroxide solution was acquired from Merck (Darmstadt, Germany).

\subsection{Preparation of C. pinnatifida Extract}

The fruits of $C$. pinnatifida were collected from Wanhua Dist., Taipei City, Taiwan, in July 2020 and identified by Prof. J.-J. Chen. A voucher specimen was deposited in the Department of Pharmacy, National Yang Ming Chiao Tung University, Taipei, Taiwan. Samples were obtained, air-dried, and cut into pieces. The amount of $125 \mathrm{~mL}$ of different solvents ( $n$-hexane, chloroform, dichloromethane, EtOAc, acetone, $\mathrm{EtOH}$, and $\mathrm{MeOH}$ ) was added into $20 \mathrm{~g}$ of pieces and shaken by orbital shakers for $24 \mathrm{~h}$ at $25^{\circ} \mathrm{C}$. The extracts were filtered through filter paper (Whatman No. 1) and condensed by a rotary evaporator at $37^{\circ} \mathrm{C}$. All extracts were stored at $-20{ }^{\circ} \mathrm{C}$ until further experiments.

\subsection{Preparation of Active Components}

The fruits $(20 \mathrm{~g})$ of $C$. pinnatifida were extracted and shredded with $\mathrm{MeOH}(3 \times 125 \mathrm{~mL}$, $3 \mathrm{~d}$ each) at room temperature. The $\mathrm{MeOH}$ extract was concentrated under reduced pressure at $37^{\circ} \mathrm{C}$, and the $\mathrm{MeOH}$ extract $(5.61 \mathrm{~g})$ was obtained. $\mathrm{MeOH}$ extract $(5.61 \mathrm{~g})$ was purified by column chromatography (CC) (220 g of silica gel, 70-230 mesh; $n$-hexane/acetone gradient) to afford 14 fractions: A1-A14. Part (153 mg) of fraction A9 was further purified by preparative TLC (silica gel; $n$-hexane/acetone, 2:1) to afford epicatechin (4.98 mg) $\left(R_{\mathrm{f}}=0.12\right)$ and procyanidin B2 $(3.81 \mathrm{mg})\left(\mathrm{R}_{\mathrm{f}}=0.35\right)$. Part $(215 \mathrm{mg})$ of fraction A11 was further by preparative TLC (silica gel; dichloromethane/ $\mathrm{MeOH}, 5: 1$ ) to obtain hyperoside $(1.70 \mathrm{mg})\left(\mathrm{R}_{\mathrm{f}}=0.30\right)$ and chlorogenic acid $(5.81 \mathrm{mg})\left(\mathrm{R}_{\mathrm{f}}=0.23\right)$. The TLC graphs of isolated compounds are shown in Figure S1. The structures of epicatechin, chlorogenic acid, hyperoside, and procyanidin B2 were identified by nuclear magnetic resonance (NMR) spectra acquired using a Bruker Avance $400 \mathrm{MHz}$ spectrometer (Bruker, Bremen, Germany).

\subsection{Reverse-Phase HPLC}

Reversed-phase separations were performed using a LiChrospher ${ }^{\circledR} 100$ RP-18 Endcapped ( $5 \mu \mathrm{m}$; column of dimensions $4.6 \times 250 \mathrm{~mm}$ ) purchased from Merck KGaA, Darmstadt, Germany. HPLC-PDA chromatographic fingerprints were obtained with an Agilent 1260 Infinity II HPLC instrument equipped with a 1260 Infinity II quaternary pump, a 1260 Infinity II degasser, a 1260 Infinity II vialsampler, a 1260 Infinity II column thermostat, a 1260 Infinity II diode array detector HS, and a PC with the Agilent Chemstation software. All of them are from Agilent Technologies (Waldbronn, Germany). Gradient separation using $0.2 \%$ acetic acid in water $(v / v)$ (solvent $\mathrm{A})$ and water:methanol:acetonitrile $=3: 2: 5$ (solvent B) as mobile phase was as follows: $0-20 \mathrm{~min}$, linear gradient from 0 to $15 \% \mathrm{~B}$; 20-65 $\mathrm{min}, 15 \%$ B with isocratic elution; $65-110 \mathrm{~min}$, linear gradient from 15 to $40 \% \mathrm{~B}$; $110-120 \mathrm{~min}$, linear gradient from 40 to $100 \% \mathrm{~B} ; 120-130 \mathrm{~min}$, back to initial conditions at $0 \% \mathrm{~B}$; and $130-135 \mathrm{~min}$, at $0 \% \mathrm{~B}$. The flow rate was $1.0 \mathrm{~mL} / \mathrm{min}$, and the injection volume was $10 \mu \mathrm{L}$. Peaks were detected at $280 \mathrm{~nm}$. Different compounds were identified by retention time. To guarantee peak purity, DAD acquisition from 200 to $650 \mathrm{~nm}$ was conducted to register UV-spectra. For the quantitative analysis of four compounds in the extracts, aliquots of samples were dispersed in $10 \mathrm{~mL}$ of a methanol solution by sonication for $5 \mathrm{~min}$. Then, the samples were centrifuged for $15 \mathrm{~min}$ at $3500 \mathrm{rpm}$, and the supernatant extracts were filtered through $0.45 \mu \mathrm{m}$ PTFE syringe filters (Zhejiang Sorfa Medical Plastic Co., Ningbo, China).

\subsection{Determination of Total Phenolic Content}

Total phenolic content (TPC) of different extracts was determined by Folin-Ciocalteau's method with a slight modification of [19]. Briefly, 0.5 N Folin-Ciocalteu reagent (50 $\mu \mathrm{L}$ ) was diluted by $\mathrm{ddH}_{2} \mathrm{O}$. Gallic acid was diluted by $\mathrm{MeOH}(0-100 \mu \mathrm{g} / \mathrm{mL})$ as standard. Each extract or gallic acid $(50 \mu \mathrm{L})$ was added to a 96-well microplate. The mixture was incubated for $5 \mathrm{~min}$. Subsequently, $20 \% \mathrm{Na}_{2} \mathrm{CO}_{3}$ solution $(100 \mu \mathrm{L})$ was added. After 
$40 \mathrm{~min}$, it was incubated in darkness at room temperature before measuring the absorbance of the supernatant at $750 \mathrm{~nm}$. The TPC of the extracts was determined from a standard calibration curve using gallic acid in the range of $0-100 \mu \mathrm{g} / \mathrm{mL}$ with $\mathrm{R}^{2}$ value of 0.9992 . The concentration of TPC was expressed in milligram (mg) gallic acid equivalents (GAE) per gram of dried extract. All measurements were conducted in triplicate.

\subsection{Determination of Total Flavonoid Content}

The total flavonoid content (TFC) of each extract was measured using the aluminum chloride colorimetry method described by Do et al. [20] with slight modifications. In short, the extracted sample was diluted with $\mathrm{MeOH}$ to reach a concentration of $100 \mu \mathrm{g} / \mathrm{mL}$. Quercetin was diluted in $\mathrm{MeOH}(0-100 \mu \mathrm{g} / \mathrm{mL})$ as standard. The diluted extract sample or quercetin $(400 \mu \mathrm{L})$ was mixed with $10 \%(w / v)$ aluminum chloride solution $(200 \mu \mathrm{L})$ and $0.1 \mathrm{mM}$ potassium acetate solution $(200 \mu \mathrm{L})$. The mixture was reacted at room temperature for $30 \mathrm{~min}$. Then, the absorbance of the mixture was measured at $415 \mathrm{~nm}$. The TFC of the extracts was determined from a standard calibration curve using quercetin with $\mathrm{R}^{2}$ value of 0.9997. The concentration of TFC was expressed in milligram quercetin equivalents (GAE) per gram of dried extract. All measurements were conducted in triplicate.

\subsection{DPPH Radical Scavenging Activity}

The scavenging activity of DPPH radical was investigated as described with slight modification [21]. DPPH solution was prepared diluted by EtOH to reach the final concentration of $200 \mu \mathrm{M}$. Different concentrations $(200,100,50,25$, and $12.5 \mu \mathrm{g} / \mathrm{mL})$ of extracts or compounds $(100 \mu \mathrm{L})$ were mixed with DPPH solution $(100 \mu \mathrm{L})$ and incubated for $30 \mathrm{~min}$ at room temperature and in darkness, and the absorbance of the mixture was measured at $520 \mathrm{~nm}$. DPPH radical scavenging activity was calculated with the following formula:

$$
\text { DPPH scavenging activity }(\%)=\left(A_{c}-A_{t}\right) / A_{c} \times 100 \text {, }
$$

where $A_{t}$ is the absorbance of the test sample, and $A_{c}$ is the absorbance of the control (untreated group). BHT was used as the positive control. All half-maximal inhibitory concentration $\left(\mathrm{IC}_{50}\right)$ values of tested activities were determined by the linear regression of the percentage of remaining DPPH radical against the sample's concentration.

\subsection{ABTS Radical Scavenging Activity}

ABTS radical scavenging activity of each extract was measured based on the method with slight changes [22]. In brief, the stock of working solution was prepared by the mix of $28 \mathrm{mM}$ ABTS solution and $9.6 \mathrm{mM}$ potassium persulfate with $\mathrm{ddH}_{2} \mathrm{O}$ (final concentration, $1 / 1, v / v$ ) and leaving the mixture in the dark for about $16 \mathrm{~h}$ at room temperature before use. The working solution was diluted by EtOH to reach the absorbance of $0.70 \pm 0.02$ at $740 \mathrm{~nm}$ for further experiments. Different concentrations $(200,100,50,20$, and $12.5 \mu \mathrm{g} / \mathrm{mL})$ of extracts or compounds $(10 \mu \mathrm{L})$ were mixed with the working solution $(190 \mu \mathrm{L})$. The mixture was incubated at room temperature for $6 \mathrm{~min}$, the antioxidant activity of the mixture was determined by calculating the decrease in absorbance measured at $740 \mathrm{~nm}$ by the following equation:

$$
\text { ABTS radical inhibiting activity }(\%)=\left(A_{c}-A_{t}\right) / A_{c} \times 100,
$$

Where $A_{c}$ and $A_{t}$ are the absorbance of the control (untreated group) and test sample, respectively. The $\mathrm{IC}_{50}$ values of all tested activities were determined by the liner regression of the percentage of remaining ABTS radical against the sample's concentration.

\subsection{Superoxide Radical Scavenging Activity}

The scavenging activity of superoxide anion radical $\left(\mathrm{O}_{2}{ }^{\bullet-}\right)$ was evaluated using a modified method [23]. NBT (300 $\mu \mathrm{M})$, NADH $(468 \mu \mathrm{M})$, and PMS $(120 \mu \mathrm{M})$ were prepared with dilution by Tris- $\mathrm{HCl}$ buffer $(16 \mathrm{mM}, \mathrm{pH} 8.0)$, respectively. An amount of $50 \mu \mathrm{L}$ of 
NBT, PMS, and different concentrations (400, 200, 10, 50, and $25 \mu \mathrm{g} / \mathrm{mL})$ of extracts or compounds were mixed. An amount of $50 \mu \mathrm{L} \mathrm{NADH}$ solution was added, and the reaction was initiated to produce superoxide radicals. The absorbance was measured at $560 \mathrm{~nm}$ after incubating at room temperature for $5 \mathrm{~min}$. The scavenging activity was measured by the following equation:

Superoxide radical scavenging activity $=\left(A_{c}-A_{t}\right) / A_{c} \times 100$,

where $A_{t}$ is the absorbance of the test sample, and $A_{c}$ is the absorbance of the control (untreated group). The $\mathrm{IC}_{50}$ values of all tested activities were determined by the linear regression of the percentage of remaining superoxide radical against the sample concentration.

\subsection{Hydroxyl Radical Scavenging Activity}

The scavenging activity of hydroxyl radical was measured based on the method described by Mathew and Abraham with slight revision [24]. In short, different concentrations $(400,200,10,50$, and $25 \mu \mathrm{g} / \mathrm{mL})$ of extracts or compounds $(200 \mu \mathrm{L})$ were mixed with working solution $(200 \mu \mathrm{L})$ contained $1 \mathrm{mM} \mathrm{FeCl}_{3}, 1 \mathrm{mM}$ EDTA, and $2.8 \mathrm{mM}$ deoxyribose. Then, $20 \mu \mathrm{L}$ ascorbic acid $(1 \mathrm{mM})$ and $100 \mu \mathrm{L} \mathrm{H}_{2} \mathrm{O}_{2}(20 \mathrm{mM})$ in sodium phosphate buffer $(20 \mathrm{mM}$ $\mathrm{pH}$ 7.4) was added. The mixture was incubated in a water bath at $37^{\circ} \mathrm{C}$ for $1 \mathrm{~h}$ to trigger the Fenton reaction and form a hydroxyl radical. After incubation, $2.8 \%$ TCA $(200 \mu \mathrm{L})$ and $1 \%$ TBA $(200 \mu \mathrm{L})$ were added and boiled in the dry bath at $100{ }^{\circ} \mathrm{C}$ for $1 \mathrm{~h}$. The mixture was measured at $532 \mathrm{~nm}$ by the following equation:

Hydroxyl radical scavenging activity $(\%)=\left(A_{c}-A_{t}\right) / A_{c} \times 100$,

where $A_{t}$ and $A_{c}$ are the absorbance of the test sample and the control (untreated group), respectively. The $\mathrm{IC}_{50}$ values of all tested activities were determined by the linear regression of the percentage of remaining hydroxyl radical against the sample's concentration.

\subsection{Ferric Reducing Antioxidant Power (FRAP)}

Ferric reducing antioxidant power was measured based on previous study with slight modification [25]. The working solution was mixed with acetate buffer ( $\mathrm{pH} 3.6$ ), ferric chloride solution $(20 \mathrm{mM})$, and TPTZ solution (10 mM TPTZ in $40 \mathrm{mM} \mathrm{HCl}$ ) in a proportion of 10:1:1, respectively, and freshly prepared before used. An amount of $900 \mu \mathrm{L}$ of the working solution was warmed to $37^{\circ} \mathrm{C}$ and then mixed with $100 \mu \mathrm{L}$ of the diluted sample, blank or standard in a microcentrifuge tube. The tubes were vortexed and in the dry bath at $37^{\circ} \mathrm{C}$ for $40 \mathrm{~min}$. Absorbance was measured at $593 \mathrm{~nm}$. The standard curve was linear between 0 and $100 \mathrm{mM}$ Trolox with an $\mathrm{R}^{2}$ value of 0.998 . Results are expressed in $\mathrm{mM}$ $\mathrm{TE} / \mathrm{g}$ dry weight. Additional dilution was needed if the FRAP value measured was over the linear range of the standard curve.

\subsection{2. $\alpha$-Glucosidase Inhibitory Activity Assay}

The inhibition assay of $\alpha$-glucosidase was conducted using the conditions previously reported with slight modifications [26]. The $\alpha$-Glucosidase solution was diluted by $0.1 \mathrm{M}$ sodium phosphate buffer ( $\mathrm{pH} 6.8)$ to $1 \mathrm{U} / \mathrm{mL}$. Different concentrations $(400,200,10,50$, and $25 \mu \mathrm{g} / \mathrm{mL})$ of extracts or compounds $(100 \mu \mathrm{L})$ were mixed with $\alpha$-glucosidase solution $(20 \mu \mathrm{L})$ in a microcentrifuge tube. Subsequently, $p$-NPG $(0.53 \mathrm{mM} ; 380 \mu \mathrm{L})$, the substrate, was added and incubated in dry baths at $37^{\circ} \mathrm{C}$ for $40 \mathrm{~min}$ after the mixture vortexed. The reaction was terminated after adding $0.1 \mathrm{M} \mathrm{Na}_{2} \mathrm{CO}_{3}$ solution $(500 \mu \mathrm{L})$. The absorbance of released $p$-nitrophenol ( $p$-PNP) was measured by calculating the decrease in absorbance measured at $400 \mathrm{~nm}$ by the following equation:

$$
\alpha \text {-Glucosidase inhibition }(\%)=\left(A_{c}-A_{t}\right) / A_{c} \times 100 \text {, }
$$


where $A_{c}$ is the absorbance of the control (untreated group), and $A_{t}$ is the absorbance of the test sample. The $\mathrm{IC}_{50}$ values of all tested activities were determined by the linear regression of the percentage of remaining $\alpha$-glucosidase against the sample concentration.

\subsection{Molecular Modeling Docking Study}

All calculations are performed by Discovery Studio 2019 (San Diego, CA, USA) software. Primarily, the structure of hyperoside or acarbose is energy minimized until the default derivative convergence criterion of $0.01 \mathrm{kcal} / \mathrm{mol}$ is met. The crystal structure (PDB: 3A4A) is retrieved from the Protein Databank, and hydrogen atoms are added to prepare the docked receptor. This protein structure is subsequently used in the CDocker program to dock hyperoside or acarbose into the active site. Ten different docking poses are calculated and ranked by using the PLP-Score scoring function. The top-ranked docking solution is visually analyzed to determine the binding mode of hyperoside or acarbose.

\subsection{Statistical Analysis}

All data are expressed as mean \pm SEM. Statistical analysis was carried out using Student's $t$-test. A probability of 0.05 or less was considered statistically significant. All experiments were performed at least 3 times.

\section{Results and Discussion}

3.1. Determination of Total Phenolic Content (TPC), Total Flavonoid Content (TFC) and Yields in Each Solvent Extract

TPCs, TFCs, and yields of various solvent extracts from C. pinnatifida were evaluated. TPCs, TFCs, and extraction yields of $n$-hexane, chloroform, dichloromethane, EtOAc, acetone, $\mathrm{EtOH}$, and $\mathrm{MeOH}$ extracts from C. pinnatifida are shown in Table 1.

Table 1. TPC, TFC, and extraction yields of Crataegus pinnatifida with each extraction solvent.

\begin{tabular}{|c|c|c|c|c|}
\hline $\begin{array}{l}\text { Extracting } \\
\text { Solvents }\end{array}$ & $\begin{array}{l}\text { Relative } \\
\text { Polarity }\end{array}$ & $\begin{array}{c}\text { TPC (mg/g) }{ }^{a} \\
\quad(G A E)\end{array}$ & $\begin{array}{c}\text { TFC (mg/g) } \\
(\mathrm{QE})\end{array}$ & Yields $(\%)^{c}$ \\
\hline n-Hexane & 0.009 & $12.12 \pm 0.26$ * & $31.74 \pm 1.07^{*}$ & $2.3 \pm 1.67$ \\
\hline Chloroform & 0.259 & $21.09 \pm 0.99^{* *}$ & $37.93 \pm 5.31 *$ & $3.2 \pm 0.79$ \\
\hline Dichloromethane & 0.269 & $19.77 \pm 0.13^{* *}$ & $34.87 \pm 1.95 *$ & $9.7 \pm 1.49$ \\
\hline Ethyl acetate & 0.228 & $63.53 \pm 0.27^{* * *}$ & $25.22 \pm 4.21^{*}$ & $15.5 \pm 1.13$ \\
\hline Acetone & 0.355 & $45.81 \pm 0.61^{* * *}$ & $19.41 \pm 3.00 *$ & $17.1 \pm 0.23$ \\
\hline Ethanol & 0.654 & $32.82 \pm 1.21^{* * *}$ & $22.61 \pm 0.90 *$ & $24.1 \pm 0.23$ \\
\hline Methanol & 0.762 & $44.20 \pm 1.30^{* * *}$ & $17.40 \pm 3.11$ & $28.0 \pm 0.75$ \\
\hline
\end{tabular}

${ }^{a}$ TPC was expressed in mg of gallic acid equivalents (GAE) per gram of extract. ${ }^{b}$ TFC was expressed in milligram of quercetin equivalents (QE) per gram of extract. Values are expressed as means \pm standard error. ${ }^{c}$ Yield was calculated as \% yield $=$ (weight of extract/initial weight of dry sample) $\times 100 ;{ }^{*} p<0.05,{ }^{* *} p<0.01,{ }^{* * *} p<0.001$ compared with the control.

The yields of various solvent extracts from C. pinnatifida ranged from $2.3 \pm 1.67 \%$ ( $n$-hexane extract) to $28.0 \pm 0.75 \%$ (MeOH extract). Higher polar solvent (including $\mathrm{MeOH}$ and $\mathrm{EtOH}$ ) extracts had higher yields. The results indicated that $C$. pinnatifida is abundant in high polar components.

Phenolic contents in different solvent extracts from $C$. pinnatifida were measured by the Folin-Ciocalteu method. TPC in the extracts was calculated from the regression equation $\left(y=0.0524 x, R^{2}=0.9989\right)$ of the calibration curve. The TPCs of solvent extracts ranged from $12.12 \pm 0.26$ to $63.53 \pm 0.27 \mathrm{mg}$ of GAE/g. Among all different solvent extracts, the EtOAc extract contained the highest amount of TPC $(63.53 \pm 0.27 \mathrm{mg} / \mathrm{g})$ followed by acetone $(45.81 \pm 0.61 \mathrm{mg} / \mathrm{g}), \mathrm{MeOH}(44.20 \pm 1.30 \mathrm{mg} / \mathrm{g}), \mathrm{EtOH}(32.82 \pm 1.21 \mathrm{mg} / \mathrm{g})$, chloroform $(21.09 \pm 0.99 \mathrm{mg} / \mathrm{g})$, dichloromethane $(19.77 \pm 0.13 \mathrm{mg} / \mathrm{g})$, and $n$-hexane $(12.12 \pm 0.26 \mathrm{mg} / \mathrm{g})$. These results suggested that solvents with higher relative polarity are suitable for the extraction of phenolic compounds from C. pinnatifida.

The TFCs of solvent extracts from $C$. pinnatifida were evaluated by aluminum chloride colorimetric method. TFC in the extracts was calculated from the regression equation 
$\left(y=0.0459 x, R^{2}=0.9997\right)$ of the calibration curve. The TFCs of different solvent extracts ranged from $17.40 \pm 3.11$ to $37.93 \pm 5.31 \mathrm{mg}$ of $\mathrm{QE} / \mathrm{g}$. Among all different solvent extracts, chloroform extract contained highest amount of TFC $(37.93 \pm 5.31 \mathrm{mg} / \mathrm{g})$ and followed by dichloromethane $(34.87 \pm 1.95 \mathrm{mg} / \mathrm{g}), n$-hexane $(31.74 \pm 1.07 \mathrm{mg} / \mathrm{g})$, EtOAc $(25.22 \pm 4.21 \mathrm{mg} / \mathrm{g}), \mathrm{EtOH}(22.61 \pm 0.90 \mathrm{mg} / \mathrm{g})$, acetone $(19.41 \pm 3.00 \mathrm{mg} / \mathrm{g})$, and $\mathrm{MeOH}$ $(17.40 \pm 3.11 \mathrm{mg} / \mathrm{g})$.

The comparative assessment of total phenolic content (TPC) and total flavonoid content (TFC) of various solvent extracts ( $n$-hexane, chloroform, dichloromethane, EtOAc, acetone, $\mathrm{EtOH}$, and $\mathrm{MeOH}$ ) from the fruits of $\mathrm{C}$. pinnatifida was first mentioned in this study. This can supply a guide for the option of suitable solvents in TPC and TFC extraction applications.

\subsection{DPPH Free Radical Scavenging Activity}

The hydrogen atom or electron donation abilities of various solvent extracts were measured by the reduction of a purple DPPH ${ }^{\bullet}$ solution to 1,1-diphenyl-2-picryl hydrazine [27,28]. Table 2 showed the DPPH radical scavenging activities of each extract. The EtOAc extract $\left(\mathrm{IC}_{50}=23.26 \pm 1.97 \mu \mathrm{g} / \mathrm{mL}\right)$ exhibited the strongest DPPH radical scavenging activity and was even better than $\mathrm{BHT}\left(\mathrm{IC}_{50}=34.28 \pm 1.40 \mu \mathrm{g} / \mathrm{mL}\right)$. In addition, acetone $\left(\mathrm{IC}_{50}=40.06 \pm\right.$ $0.18)$, chloroform $\left(\mathrm{IC}_{50}=68.61 \pm 3.14 \mu \mathrm{g} / \mathrm{mL}\right)$, dichloromethane $\left(\mathrm{IC}_{50}=76.22 \pm 4.90 \mu \mathrm{g} / \mathrm{mL}\right)$, $\mathrm{MeOH}\left(\mathrm{IC}_{50}=74.13 \pm 5.61 \mu \mathrm{g} / \mathrm{mL}\right)$, and $\mathrm{EtOH}\left(\mathrm{IC}_{50}=96.21 \pm 4.26 \mu \mathrm{g} / \mathrm{mL}\right)$ extracts showed moderate activities. $n$-Hexane $\left(\mathrm{IC}_{50}=199.18 \pm 16.82 \mu \mathrm{g} / \mathrm{mL}\right)$ extract showed relatively high $\mathrm{IC}_{50}$ value.

Table 2. The antioxidant activities of different solvent extracts from Crataegus pinnatifida determined by DPPH, ABTS, superoxide, and hydroxyl radical scavenging and FRAP assays.

\begin{tabular}{|c|c|c|c|c|c|}
\hline $\begin{array}{l}\text { Extracting } \\
\text { Solvents }\end{array}$ & $\begin{array}{c}\text { DPPH } \\
\mathrm{IC}_{50}(\mu \mathrm{g} / \mathrm{mL})\end{array}$ & $\begin{array}{c}\text { ABTS } \\
\mathrm{IC}_{50}(\mu \mathrm{g} / \mathrm{mL})\end{array}$ & $\begin{array}{l}\text { Superoxide } \\
\mathrm{IC}_{50}(\mu \mathrm{g} / \mathrm{mL})\end{array}$ & $\begin{array}{c}\text { Hydroxyl } \\
\text { IC }_{50}(\mu \mathrm{g} / \mathrm{mL})\end{array}$ & $\begin{array}{l}\text { FRAP }(\mathrm{mM} M / g) \\
(T E)^{b}\end{array}$ \\
\hline n-Hexane & $199.18 \pm 16.82 *$ & $131.14 \pm 7.15 *$ & $>400$ & $124.45 \pm 6.27 *$ & $70.11 \pm 4.13 *$ \\
\hline Chloroform & $68.61 \pm 3.14^{*}$ & $141.97 \pm 3.70 *$ & $>400$ & $114.41 \pm 1.80 *$ & $149.98 \pm 5.54$ * \\
\hline Dichloromethane & $76.22 \pm 4.90 *$ & $131.44 \pm 7.13^{*}$ & $>400$ & $>400$ & $154.05 \pm 4.62 * *$ \\
\hline Ethyl acetate & $23.26 \pm 1.97^{* *}$ & $50.73 \pm 8.03 *$ & $122.95 \pm 9.07 *$ & $92.30 \pm 7.47$ * & $216.32 \pm 9.13 *$ \\
\hline Acetone & $40.06 \pm 0.18 * *$ & $87.75 \pm 2.70 * *$ & $>400$ & $127.25 \pm 2.26$ * & $264.27 \pm 12.11 *$ \\
\hline Ethanol & $96.21 \pm 4.26 * *$ & $140.29 \pm 6.76^{*}$ & $>400$ & $139.03 \pm 17.33$ * & $227.59 \pm 10.13 *$ \\
\hline Methanol & $74.13 \pm 5.61^{* *}$ & $105.86 \pm 6.25 *$ & $242.95 \pm 18.51$ & $138.04 \pm 21.91$ * & $198.94 \pm 8.24 *$ \\
\hline $\mathrm{BHT}^{\mathrm{a}}$ & $34.28 \pm 1.40^{*}$ & $12.34 \pm 0.29 *$ & N.A. ${ }^{c}$ & $61.51 \pm 2.46^{*}$ & $4257.97 \pm 44.90 * *$ \\
\hline
\end{tabular}

Results are expressed as half inhibitory concentration $\left(\mathrm{IC}_{50}\right)$ of each free-radical scavenging activity. ${ }^{\text {a }}$ Butylated hydroxytoluene (BHT) used as positive control. ${ }^{b}$ FRAP was expressed in millimolar (mM) of Trolox equivalents (TE) per gram of extract; ${ }^{\mathrm{C}}$ N.A. indicates not available; ${ }^{*} p<0.05$, and ${ }^{* *} p<0.01$ compared with the control.

\subsection{ABTS Free-Radical Scavenging Activity}

The ABTS assay is based on the generation of a blue/green $\mathrm{ABTS}^{\bullet+}$ that can be reduced by antioxidants. The high-pigmented and hydrophilic antioxidants were better reflected by ABTS assay than DPPH assay [28]. As shown in Table 2, the EtOAc extract also exhibited relatively effective ABTS radical scavenging activity $\left(\mathrm{IC}_{50}=50.73 \pm 8.03 \mu \mathrm{g} / \mathrm{mL}\right)$ followed by acetone $\left(\mathrm{IC}_{50}=87.75 \pm 2.70 \mu \mathrm{g} / \mathrm{mL}\right), \mathrm{MeOH}\left(\mathrm{IC}_{50}=105.86 \pm 6.25 \mu \mathrm{g} / \mathrm{mL}\right)$, $n$-hexane $\left(\mathrm{IC}_{50}=131.14 \pm 7.15 \mu \mathrm{g} / \mathrm{mL}\right)$, dichloromethane $\left(\mathrm{IC}_{50}=131.44 \pm 7.13 \mu \mathrm{g} / \mathrm{mL}\right)$, $\mathrm{EtOH}\left(\mathrm{IC}_{50}=140.29 \pm 6.76\right)$, and chloroform $\left(\mathrm{IC}_{50}=141.97 \pm 3.70 \mu \mathrm{g} / \mathrm{mL}\right)$.

\subsection{Superoxide Radical Scavenging Activity}

This assay is measured by the PMS/NADH-NBT system. Superoxide anion radicals generated from dissolved oxygen by PMS/NADH coupling reaction reduce NBT. The decrease in absorbance at $560 \mathrm{~nm}$ with antioxidants indicates a reduction in superoxide anion radicals in the reaction mixture [29]. The results are shown in Table 2, and only EtOAc extract exerted a significant effect $\left(\mathrm{IC}_{50}=122.95 \pm 9.07 \mu \mathrm{g} / \mathrm{mL}\right)$ on the superoxide radical scavenging assay. 


\subsection{Hydroxyl Radical Scavenging Activity}

This assay evaluated the abilities of the extracts to suppress the degradation of hydroxyl radical bases on a Fenton reaction model system containing $\mathrm{FeCl}_{3}$-EDTA-ascorbic acid and $\mathrm{H}_{2} \mathrm{O}_{2}$ [30]. EtOAc extract $\left(\mathrm{IC}_{50}=92.30 \pm 7.47 \mu \mathrm{g} / \mathrm{mL}\right)$ showed relatively potent antioxidant activity in scavenging hydroxyl radical followed by chloroform $\left(\mathrm{IC}_{50}=114.41 \pm 1.80 \mu \mathrm{g} / \mathrm{mL}\right)$, $n$-hexane $\left(\mathrm{IC}_{50}=124.45 \pm 6.27 \mu \mathrm{g} / \mathrm{mL}\right)$, acetone $\left(\mathrm{IC}_{50}=127.25 \pm 2.26 \mu \mathrm{g} / \mathrm{mL}\right), \mathrm{MeOH}$ $\left(\mathrm{IC}_{50}=138.04 \pm 21.91 \mu \mathrm{g} / \mathrm{mL}\right)$, and EtOH $\left(\mathrm{IC}_{50}=139.03 \pm 17.33 \mu \mathrm{g} / \mathrm{mL}\right)($ Table 2$)$.

\subsection{Ferric Reducing Antioxidant Power}

The assay measures the antioxidant potential of each extract through a reduction of ferric iron $\left(\mathrm{Fe}^{3+}\right)$ complex to ferrous iron $\left(\mathrm{Fe}^{2+}\right)$ complex by antioxidants present in the samples [31]. Acetone extract exhibited highest ferric reducing antioxidant powers $(264.27 \pm 12.11 \mathrm{TE} \mathrm{mM} / \mathrm{g})$. In addition, EtOH $(227.59 \pm 10.13 \mathrm{TE} \mathrm{mM} / \mathrm{g})$, EtOAc $(216.32 \pm 9.13 \mathrm{TE} \mathrm{mM} / \mathrm{g})$, and $\mathrm{MeOH}$ extracts $(198.94 \pm 8.24 \mathrm{TE} \mathrm{mM} / \mathrm{g})$ showed relatively high reducing ability followed by dichloromethane (154.05 $\pm 4.62 \mathrm{TE} \mathrm{mM} / \mathrm{g})$, chloroform $(149.98 \pm 5.54 \mathrm{TE} \mathrm{mM} / \mathrm{g})$, and $n$-hexane $(70.11 \pm 4.13 \mathrm{TE} \mathrm{mM} / \mathrm{g})$ (Table 2$)$.

Based on the above results of the antioxidant assays, the EtOAc extract from C. pinnatifida possessed the highest phenolic content and the highest hydrogen atom or electron donation abilities in DPPH and ABTS radical scavenging assays. In addition, the EtOAc extract also showed potent superoxide and hydroxyl radical scavenging effects. Moreover, acetone extract showed the highest reducing ability in the FRAP assay.

The comparative evaluation of antioxidant assays (DPPH, ABTS, superoxide, hydroxyl, and FRAP) of various solvent extracts ( $n$-hexane, chloroform, dichloromethane, EtOAc, acetone, $\mathrm{EtOH}$, and $\mathrm{MeOH}$ ) from the fruits of $C$. pinnatifida was first proposed in our study. This can provide an indication for the selection of appropriate solvents in antioxidant extraction applications.

\subsection{Anti- $\alpha$-Glucosidase Activity Assay}

$\alpha$-Glucosidase inhibitors decrease the rate of hydrolytic cleavage of oligosaccharide and delay carbohydrate digestion [32,33]. The results shown in Table 3, the acetone extract of $C$. pinnatifida exerted the most anti- $\alpha$-glucosidase activity $\left(\mathrm{IC}_{50}=42.35 \pm 2.48 \mu \mathrm{g} / \mathrm{mL}\right)$ followed by $\mathrm{MeOH}\left(\mathrm{IC}_{50}=52.02 \pm 0.24 \mu \mathrm{g} / \mathrm{mL}\right), \mathrm{EtOH}\left(\mathrm{IC}_{50}=58.69 \pm 6.91 \mu \mathrm{g} / \mathrm{mL}\right)$, $n$-hexane $\left(\mathrm{IC}_{50}=99.75 \pm 4.37 \mu \mathrm{g} / \mathrm{mL}\right)$, dichloromethane $\left(\mathrm{IC}_{50}=120.41 \pm 6.44 \mu \mathrm{g} / \mathrm{mL}\right)$, EtOAc $\left(\mathrm{IC}_{50}=126.36 \pm 9.81 \mu \mathrm{g} / \mathrm{mL}\right)$, and chloroform $\left(\mathrm{IC}_{50}=207.46 \pm 9.52 \mu \mathrm{g} / \mathrm{mL}\right)$. Seven solvent extracts showed higher anti- $\alpha$-glucosidase activities than antidiabetic agent, acarbose $\left(\mathrm{IC}_{50}=317.80 \pm 16.36\right)$. Among all solvent extracts, acetone, $\mathrm{MeOH}$, and $\mathrm{EtOH}$ extracts showed relatively potent anti- $\alpha$-glucosidase activity. These results indicated that the suitable relative polarity of extracting solvents for anti- $\alpha$-glucosidase activity from $C$. pinnatifida would be ranged from 0.355 to 0.762 .

\subsection{Quantitation of Active Components in Different Solvent Extracts}

Figures S2-S9 displayed the quantification of active components in different solvent extracts from C. pinnatifida by HPLC analysis with reverse-phase. The contents of four active compounds in each solvent extract was shown in Table 4. Total amount of four active compounds in each extract ranged from a maximum of $33.62 \pm 0.49 \mu \mathrm{g} / \mathrm{kg}$ (EtOH extract) to a minimum of $1.92 \pm 0.25 \mu \mathrm{g} / \mathrm{kg}$ ( $n$-hexane extract) in succeeding order of $\mathrm{EtOH}>\mathrm{MeOH}>\mathrm{EtOAc}>$ acetone $>$ dichloromethane $>$ chloroform $>n$-hexane extract. $\mathrm{EtOH}(33.62 \pm 0.49 \mu \mathrm{g} / \mathrm{kg})$ and $\mathrm{MeOH}(27.76 \pm 0.45 \mu \mathrm{g} / \mathrm{kg})$ extracts exhibited higher amounts of four active compounds compared with other extracts. Procyanidin B2 was the most abundant among the four active compounds in organic solvent extract followed by chlorogenic acid, epicatechin, and hyperoside.

The comparative evaluation for identification and quantification of the major active components (epicatechin, chlorogenic acid, hyperoside, and procyanidin B2) of different 
solvent extracts ( $n$-hexane, chloroform, dichloromethane, EtOAc, acetone, EtOH, and $\mathrm{MeOH}$ ) from the fruits of $C$. pinnatifida by HPLC analysis is first conducted in our study.

Table 3. $\alpha$-Glucosidase inhibitory activities of different solvent extracts.

\begin{tabular}{cc}
\hline Extracting Solvents & $\begin{array}{c}\alpha \text {-Glucosidase } \\
\text { IC }_{\mathbf{5 0}}(\mu \mathrm{g} / \mathrm{mL})\end{array}$ \\
\hline n-Hexane & $99.75 \pm 4.37^{*}$ \\
Chloroform & $207.46 \pm 9.52^{*}$ \\
Dichloromethane & $120.41 \pm 6.44^{*}$ \\
Ethyl acetate & $126.36 \pm 9.81^{*}$ \\
Acetone & $42.35 \pm 2.48^{* *}$ \\
Ethanol & $58.69 \pm 6.91^{*}$ \\
Methanol & $52.02 \pm 0.24^{* *}$ \\
Acarbose $^{\text {a }}$ & $317.80 \pm 16.36^{*}$ \\
\hline a Acarbose used as positive control $* p<0.05$ and $^{* *} p<0.01$ compared with the control.
\end{tabular}

Table 4. Identification and quantification of the major active components from Crataegus pinnatifida in different solvent extracts.

\begin{tabular}{cccccc}
\hline $\begin{array}{c}\text { Extracting } \\
\text { Solvents }\end{array}$ & $\begin{array}{c}\text { Epicatechin } \\
(\mu \mathrm{g} / \mathbf{k g})\end{array}$ & $\begin{array}{c}\text { Chlorogenic } \\
\text { Acid } \\
(\boldsymbol{\mu g} / \mathbf{k g})\end{array}$ & $\begin{array}{c}\text { Hyperoside } \\
(\mu \mathbf{g} / \mathbf{k g})\end{array}$ & $\begin{array}{c}\text { Procyanidin B2 } \\
(\boldsymbol{\mu g} / \mathbf{k g})\end{array}$ & $\begin{array}{c}\text { Total Amount } \\
(\boldsymbol{\mu g} / \mathbf{k g})\end{array}$ \\
\hline $\begin{array}{c}n \text {-Hexane } \\
\text { Chloroform }\end{array}$ & $0.45 \pm 0.17$ & $0.44 \pm 0.28$ & $0.63 \pm 0.32$ & $0.42 \pm 0.24$ & $1.92 \pm 0.25$ \\
Dichloromethane & $2.03 \pm 0.16$ & $1.64 \pm 0.16$ & $1.26 \pm 0.22$ & $0.82 \pm 0.13$ & $4.75 \pm 0.17$ \\
Ethyl acetate & $0.86 \pm 0.13$ & $15.43 \pm 0.62$ & $1.62 \pm 0.21$ & $1.52 \pm 0.18$ & $19.43 \pm 0.29$ \\
Acetone & $2.84 \pm 0.62$ & $3.85 \pm 0.62$ & $4.24 \pm 0.24$ & $6.21 \pm 0.36$ & $17.14 \pm 0.46$ \\
Ethanol & $12.43 \pm 0.52$ & $3.85 \pm 0.62$ & $3.71 \pm 0.48$ & $13.63 \pm 0.33$ & $33.62 \pm 0.49$ \\
Methanol & $3.73 \pm 0.42$ & $6.27 \pm 0.38$ & $3.30 \pm 0.38$ & $14.49 \pm 0.62$ & $27.76 \pm 0.45$ \\
\hline
\end{tabular}

Results are expressed as micrograms of each compound in kilogram of extract.

\subsection{Antioxidant Activities of Isolated Components}

The isolated compounds, epicatechin, chlorogenic acid, hyperoside, and procyanidin B2 (Figure 1), were measured for their antioxidant effects, including ABTS, DPPH, hydroxyl, and superoxide radical scavenging activities. Results are shown in Table 5, four isolated compounds showed potent DPPH and ABTS radical scavenging activities. Hyperoside $\left(\mathrm{IC}_{50}=10.59 \pm 0.22 \mu \mathrm{g} / \mathrm{mL}\right.$ ) exerted a higher superoxide radical scavenging activity than other isolated compounds. Epicatechin $\left(\mathrm{IC}_{50}=20 \pm 3.49 \mu \mathrm{g} / \mathrm{mL}\right)$, chlorogenic acid $\left(\mathrm{IC}_{50}=18.38 \pm 0.56 \mu \mathrm{g} / \mathrm{mL}\right)$, and procyanidin $\mathrm{B} 2\left(\mathrm{IC}_{50}=13.69 \pm 1.88 \mu \mathrm{g} / \mathrm{mL}\right) \mathrm{sig}-$ nificantly inhibited hydroxyl radical with a lower $\mathrm{IC}_{50}$ value than positive control, BHT $\left(\mathrm{IC}_{50}=60.62 \pm 2.58 \mu \mathrm{g} / \mathrm{mL}\right)$. The antioxidant activities of isolates were also evaluated by FRAP assay. Hyperoside, epicatechin, and procyanidin B2 show higher antioxidant power $(\mathrm{TE} \geq 7726.67 \pm 39.97 \mathrm{mM} / \mathrm{g})$ than BHT $(\mathrm{TE}=4257.97 \pm 44.90 \mathrm{mM} / \mathrm{g})$.

Table 5. The antioxidant activities of isolated components from Crataegus pinnatifida determined by DPPH, ABTS, superoxide, and hydroxyl radical scavenging and FRAP assays.

\begin{tabular}{cccccc}
\hline Compounds & $\begin{array}{c}\text { DPPH } \\
\mathbf{I C}_{\mathbf{5 0}}(\boldsymbol{\mu g} / \mathbf{m L})\end{array}$ & $\begin{array}{c}\text { ABTS } \\
\mathbf{I C}_{\mathbf{5 0}}(\boldsymbol{\mu g} / \mathbf{m L})\end{array}$ & $\begin{array}{c}\text { Superoxide } \\
\mathbf{I C}_{\mathbf{5 0}}(\boldsymbol{\mu g} / \mathbf{m L})\end{array}$ & $\begin{array}{c}\text { Hydroxyl } \\
\mathbf{I C}_{\mathbf{5 0}}(\boldsymbol{\mu g} / \mathbf{m L})\end{array}$ & $\begin{array}{c}\text { FRAP (mM/g) } \\
(\mathbf{T E})\end{array}$ \\
\hline Hyperoside & $5.29 \pm 0.17^{* *}$ & $18.00 \pm 0.16^{*}$ & $10.59 \pm 0.22^{* *}$ & N.A. & $7726.67 \pm 39.97$ \\
Epicatechin & $2.53 \pm 0.25^{*}$ & $3.75 \pm 0.03^{* *}$ & $41.56 \pm 0.20^{*}$ & $20 \pm 3.49$ & $13,165.19 \pm 42.42$ \\
Chlorogenic acid & $4.85 \pm 0.11^{* *}$ & $8.68 \pm 0.08^{*}$ & $99.62 \pm 1.862^{*}$ & $18.38 \pm 0.56^{* *}$ & $3684.74 \pm 34.19$ \\
Procyanidin B2 $_{\text {BHT }}{ }^{*}$ & $2.81 \pm 0.08^{*}$ & $2.91 \pm 0.57^{* *}$ & $37.22 \pm 0.63^{*}$ & $13.69 \pm 1.88^{* *}$ & $11,092.44 \pm 32.92$ \\
& $24.04 \pm 4.40^{* *}$ & $16.13 \pm 3.29^{* *}$ & N.A. ${ }^{*}$ & $60.62 \pm 2.58^{*}$ & $4257.97 \pm 44.90^{* *}$ \\
\hline
\end{tabular}

Results are expressed as half inhibitory concentration $\left(\mathrm{IC}_{50}\right)$ of each free-radical scavenging activity. ${ }^{\text {a }}$ Butylated hydroxytoluene (BHT) used as positive control. ${ }^{\mathrm{b}}$ FRAP was expressed in $\mathrm{mM}$ of Trolox equivalents (TE) per gram of extract. ${ }^{\mathrm{C}}$ N.A. indicates not available; ${ }^{*} p<0.05,{ }^{* *} p<0.01$, and ${ }^{* * *} p<0.001$ compared with the control. 


\subsection{Anti- $\alpha$-Glucosidase Activities of Isolated Components}

The inhibitory activity of four isolated compounds from $C$. pinnatifida against $\alpha$ glucosidase is shown in Table 6 . The results showed that the inhibitory activities of four isolated compounds against $\alpha$-glucosidase were stronger than the positive control (acarbose, $\mathrm{IC}_{50}=317.80 \pm 16.36 \mu \mathrm{g} / \mathrm{mL}$ ). Hyperoside and epicatechin displayed significant activities with $\mathrm{IC}_{50}$ values of $34.98 \pm 0.89$ and $81.79 \pm 6.94 \mu \mathrm{g} / \mathrm{mL}$ followed by procyanidin B2 $\left(\mathrm{IC}_{50}=118.44 \pm 7.34 \mu \mathrm{g} / \mathrm{mL}\right)$ and chlorogenic acid $\left(\mathrm{IC}_{50}=170.37 \pm 10.68 \mu \mathrm{g} / \mathrm{mL}\right)$.<smiles>Oc1cc(O)c2c(c1)OC(c1ccc(O)c(O)c1)C(O)C2</smiles><smiles>O=c1c(OC2OC(CO)C(O)C(O)[C@H]2O)c(-c2ccc(O)c(O)c2)oc2cc(O)cc(O)c12</smiles><smiles>O=C(/C=C/c1ccc(O)c(O)c1)OC1C[C@](O)(C(=O)O)C[C@H](O)[C@H]1O</smiles>

2<smiles>Oc1cc(O)c2c(c1)O[C@H](c1ccc(O)c(O)c1)[C@H](O)C2c1c(O)cc(O)c2c1O[C@H](c1ccc(O)c(O)c1)[C@H](O)C2</smiles>

Figure 1. Chemical structures of epicatechin (1), chlorogenic acid (2), hyperoside (3), and procyanidin B2 (4) from C. pinnatifida.

Table 6. $\alpha$-Glucosidase inhibitory activities of isolated compounds.

\begin{tabular}{cc}
\hline Extracting Solvents & $\alpha$-Glucosidase \\
& IC $_{\mathbf{5 0}}(\mu \mathrm{g} / \mathbf{m L})$ \\
\hline Epicatechin & $81.79 \pm 6.94^{*}$ \\
Chlorogenic acid & $170.37 \pm 10.68$ \\
Hyperoside & $34.98 \pm 0.89^{* *}$ \\
Procyanidin B2 $^{\text {Acarbose }}{ }^{\text {a }}$ & $118.44 \pm 7.34$ \\
Acar $^{*}$ & $317.80 \pm 16.36^{*}$ \\
\hline
\end{tabular}

a Acarbose used as positive control; ${ }^{*} p<0.05$ and ${ }^{* *} p<0.01$ compared with the control.

\subsection{Molecular Modeling Docking}

According to the results of anti- $\alpha$-glucosidase assay, hyperoside exhibited the most potent anti- $\alpha$-glucosidase activity among all isolated compounds. Thus, the interaction between $\alpha$-glucosidase and hyperoside was evaluated by molecular modeling docking. The $3 \mathrm{D}$ crystal structure of $\alpha$-glucosidase showed that it mainly contains numerous structural domains including the N-terminal domain, the barrel domain in which the active site is located, and the C-terminal domain. The $\alpha$-glucosidase active site is primarily formed by numerous $\beta$-sheets and several loops or $\alpha$-helices. Importantly, the active site from different species shows certain conformational similarities. It mainly contains hydrophilic residues and can accept compounds with distinct sizes to enter. The crystal structure of $\alpha$-glucosidase from beta vulgaris complexed with acarbose (Figure 2a; PDB: 3W37) reveals that its active site is not deep but wide enough to allow acarbose to enter in the flat 
conformation [34]. Due to containing four glucosyl-like groups, acarbose mainly interacts with the active site by significant $\mathrm{H}$-bond interactions including (1) the 2-hydroxyl group on the A ring interacting with Arg 552 by acting as the H-bond donor; (2) the amino linker between A and B rings makes H-bond contact with Asp 568 and Arg 552; (3) on the B ring, the $3^{\prime}$-hydroxyl group interacts with Arg 552 by acting as the H-bond acceptor and the 2'-hydroxyl group makes hydrophilic contact with Asp 232 by acting as the H-bond donor; (4) the oxygen atom on the ether moiety of the D ring makes H-bond interactions with Asn 237.

(a)

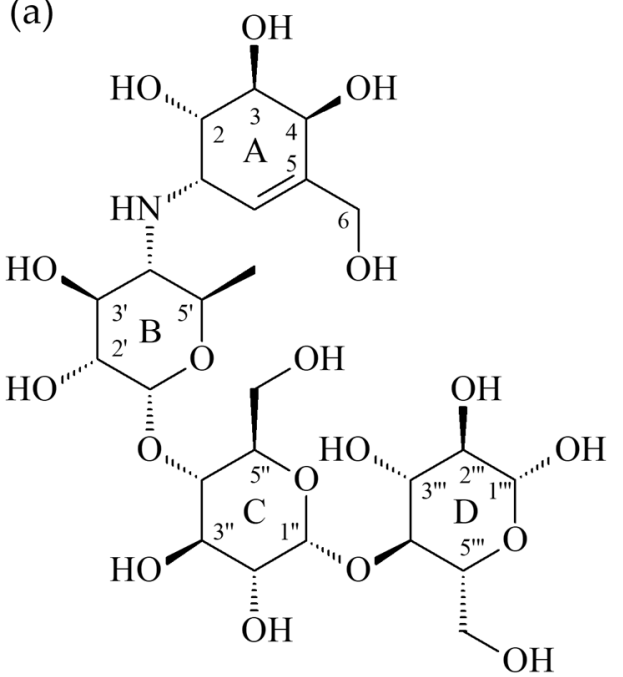

(b)

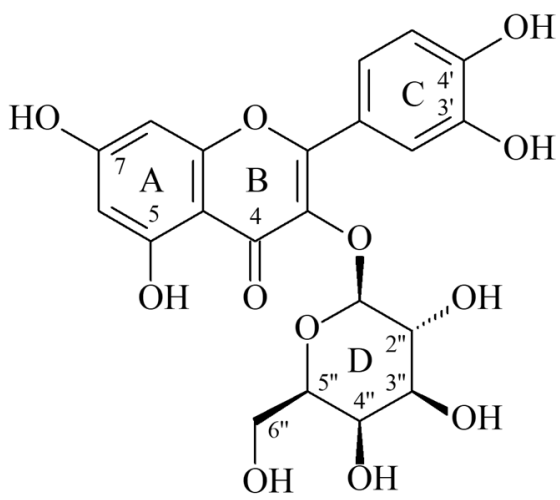

Figure 2. The structures of acarbose (a) and hyperoside (b).

To further study how hyperoside (Figure $2 b$ ) might interact with $\alpha$-glucosidase of Saccharomyces cerevisiae to exhibit its antagonistic effect, the docking models of hyperoside were generated by Discovery Studio 2019 (Accelrys, San Diego, USA) CDocker modeling program. The 3D crystal structure for $\alpha$-glucosidase of Saccharomyces cerevisiae is not available at this moment; thus, the crystal structure (PDB: 3A4A) of Saccharomyces cerevisiae (PDB: 3A4A) containing 72\% sequence homology with $\alpha$-glucosidase from Saccharomyces cerevisiae is usually used to perform the docking study and is also employed in this study. In the crystal structure (PDB: $3 \mathrm{~A} 4 \mathrm{~A}$ ), the configuration of its active site is quite similar to that of $\alpha$-glucosidase from beta vulgaris, but it is deep and narrow. The crystal structure of this active site reveals that its co-crystallized ligand, $\alpha$-D-glucopyranose, locates deeply in the ligand-binding pocket and makes three essential H-bond interactions including (1) the 4-hydroxyl group interacting with His 351 and Asp 352 by acting as the H-bond donor; (2) the 5-hydroxyl group that makes H-bond contact with Glu 277 as well as Asp 352 by acting as the H-bond donor and also serves as the H-bond acceptor to interact with Arg 213; and (3) the 6-hydroxymethyl group that acts as the H-bond donor to interact with Glu 277 and Asp 352.

As shown in Figure 3a, the docking model of hyperoside indicated that hyperoside did not enter the active site in the flat conformation due to the narrow entrance. Alternatively, the A ring of hyperoside leaned toward the binding position of $\alpha$-D-glucopyranose and the D ring of hyperoside located nearby the entrance of the active site. Importantly, hyperoside made some significant hydrophilic interactions, including the following: (1) the 5-hydroxyl and 7-hydroxyl groups on the A ring both served as the H-bond donors to interact with Asp 69 and Asp 215, respectively; (2) the 4-keto group on the B ring behaved as the H-bond acceptor to make contact with Arg 442; (3) both 3'-hydroxyl and 4'-hydroxyl groups on the A ring acted as the $\mathrm{H}$-bond donors to interact with His 280 and Asp 307 respectively; and (4) the $5^{\prime \prime}$-hydroxyl group on the D ring acted as the H-bond donor to interact with Glu 411 and the $6^{\prime \prime}$-hydroxymehtyl group also on the D ring behaved as the H-bond acceptor to contact with the amido side chain of Asn 415. Apart from hydrophilic interaction, 
hyperoside also made important hydrophobic contact: the $\pi-\pi$ interaction between its $B$ ring and Tyr 158.

(a)

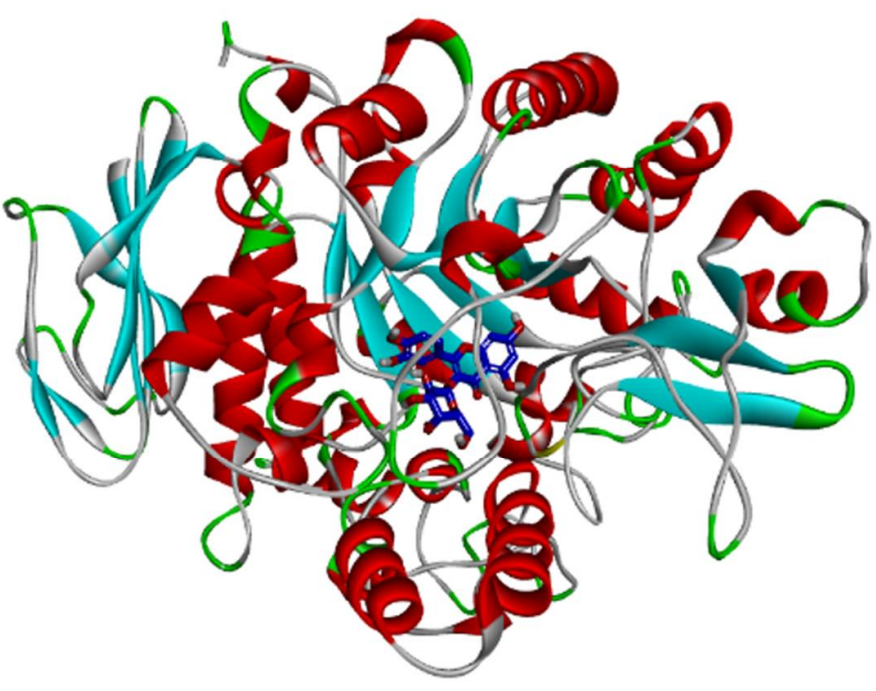

(b)

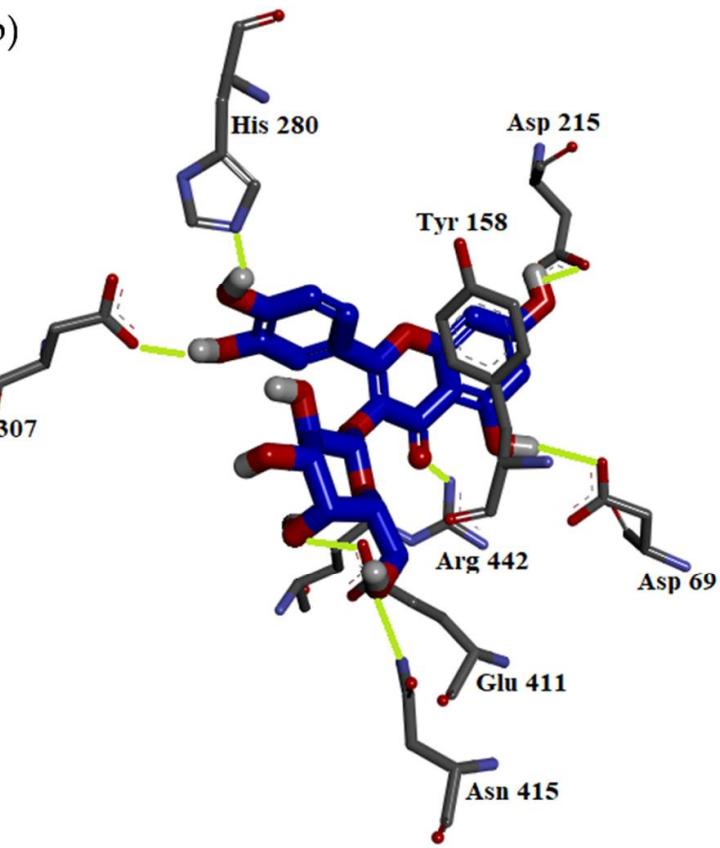

Figure 3. Interaction of hyperoside with active sites of $S$. cerevisiae $\alpha$-glucosidase. The docking model between hyperoside and $\alpha$-glucosidase (a). The hydrophilic binding mode between hyperoside and $\alpha$-glucosidase (b).

As the positive control, the docking model for acarbose is also generated to compare its binding mode with hyperoside. Acarbose was bound to the catalytic site similarly as hyperoside by leaning its A ring toward the binding position of $\alpha$-D-glucopyranose and located its D ring to protrude out of the entrance of the active site. Since it contains a lot of hydrophilic moieties, acarbose mainly interacted with the active site by the $\mathrm{H}$ bond interactions, including the following: (1) the 5-hydroxymethyl group on the A ring interacted with Asp 215 by acting as the H-bond donor; (2) the 4-hydroxyl group on the A ring interacted with His 351 as well as Asp 352 by acting as the H-bond donor and also served as the H-bond acceptor to contact with Arg 442; (3) the 5"'-hydroxymethyl group on the $\mathrm{C}$ ring interacted with His 280 by acting as the H-bond donor; (4) the $1^{\prime \prime \prime}$-hydroxyl group on the D ring made H-bond interaction with Lys 156 as well as Ser 240 by acting as the H-bond acceptor, and it also made H-bond contact with Leu 313 by acting as the H-bond donor; (5) the $2^{\prime \prime \prime}$-hydroxyl group on the D ring interacted with the backbone of Pro 312 as the H-bond donor; and (6) the $3^{\prime \prime \prime}$-hydroxyl group on the D ring contacted with the side chain of Asp 242 by serving as the H-bond donor.

For the comparison of the binding modes of hyperoside and acarbose, hyperoside can reside in the middle of the substrate binding pocket and its $\mathrm{D}$ ring is located at the entrance of the pocket to block the entrance and enhance its inhibitory effect. For acarbose, its A ring can be located in a similar position as the A ring of hyperoside but its $\mathrm{D}$ ring partially protrudes out of the substrate-binding pocket. For their hydrophilic interactive binding mode (Figure $3 b$ ), the A rings of hyperoside and acarbose exert similar binding modes. The $\mathrm{B}$ and $\mathrm{C}$ rings of hyperoside not only make significant hydrophilic but also hydrophobic interactions with the residues in the middle of the substrate-binding pocket. The $\mathrm{B}$ and $\mathrm{C}$ rings of acarbose exert only one hydrophilic interaction and they are surrounded by some hydrophobic residues including Tyr 158, Phe 159, and Phe 178; thus, their numerous hydroxyl moieties might not be able to exhibit significant hydrophobic interactions as the $\mathrm{B}$ ring of hyperoside. Moreover, the $\mathrm{D}$ ring of hyperoside resides at the entrance of the substrate-binding pocket to block the entrance through two essential 
$\mathrm{H}$-bond interactions but the $\mathrm{D}$ ring of acarbose protrudes out of the pocket and exerts its interactions with the residues outside of the pocket. The interaction with the residue in the pocket should contribute more to the antagonistic effect than that with the residue out of the pocket. All modeling results shown above highly indicate that acarbose might have a lesser antagonistic effect than hyperoside due to the difference in the binding mode. However, to generate the crystal structure of the $\alpha$-glucosidase from Saccharomyces cerevisiae complexed with hyperoside or acarbose is needed to further establish the nature of their respective interaction.

\section{Conclusions}

Various solvent extracts of C. pinnatifida and its isolated compounds were investigated with different antioxidant systems and anti- $\alpha$-glucosidase activity assay. Ethyl acetate extract from C. pinnatifida showed significant antioxidant activities through DPPH, ABTS, superoxide, hydroxyl radical scavenging tests, and FRAP assay. TPC in the extract of ethyl acetate also showed the highest value among all solvent extracts, indicating that the ethyl acetate extract possessed the largest amounts of polyphenols, and it corresponded to the results of antioxidant activities. The acetone extract possessed relatively high ferric reducing antioxidant power among all solvent extracts. In addition, acetone extract also showed the strongest $\alpha$-glucosidase inhibitory property.

Four isolated compounds from $C$. pinnatifida were quantified by HPLC and identified as epicatechin, chlorogenic acid, hyperoside, and procyanidin B2. The bioactivity assays demonstrated that all isolates displayed antioxidant activities. In addition, hyperoside showed strong anti- $\alpha$-glucosidase property. As the result of molecular modeling docking, hyperoside also exhibited the high affinity with $\alpha$-glucosidase and, thus, displayed potential inhibitory activity against $\alpha$-glucosidase.

The comparative evaluation of antioxidant and anti- $\alpha$-glucosidase activities in various solvent extracts and bioactive compounds from the fruits of $C$. pinnatifida is first mentioned in this study. The results are enough to support the importance of the suitable solvents to extract bioactive compounds. The bioactive extracts and their isolated compounds mentioned above can be used as natural antioxidants in the food industry and dietary supplements against oxidative damage. Furthermore, the acetone extract and hyperoside can also be used as natural $\alpha$-glucosidase inhibitors.

Supplementary Materials: The following supporting information can be downloaded at: https: / / www.mdpi.com/article/10.3390/antiox11020320/s1, Table S1: Retention time, LODs, LOQs, and regression analysis for four components in Crataegus pinnatifida in reverse-phase. Figure S1: The TLC graphs of isolated compounds. Figure S2: HPLC chromatogram of isolated pure compounds in reverse-phase Figure S3: Reverse-phase HPLC chromatogram of methanol extract. Figure S4: Reverse-phase HPLC chromatogram of ethanol extract. Figure S5: Reverse-phase HPLC chromatogram of acetone extract. Figure S6: Reverse-phase HPLC chromatogram of ethyl acetate extract. Figure S7: Reverse-phase HPLC chromatogram of dichloromethane extract. Figure S8: Reverse-phase HPLC chromatogram of chloroform extract. Figure S9: Reverse-phase HPLC chromatogram of $n$-hexane extract.

Author Contributions: Y.-T.L. performed isolation, structure elucidation of the constituents, bioassay, analyzed the data, and manuscript writing. H.-R.L. conducted molecular docking. C.-S.Y. analyzed quantification of components and manuscript writing. C.-C.L. carried out NMR experiments. P.-J.S., Y.-H.K. and M.-J.C. helped with structure elucidation. J.-J.C. planned, designed, and organized all the research of this study and the preparation of the manuscript. All authors have read and agreed to the published version of the manuscript.

Funding: This research was supported by a grant from the Ministry of Science and Technology (MOST), Taiwan (No. MOST 109-2320-B-010-029-MY3), awarded to J.-J. Chen.

Institutional Review Board Statement: Not applicable.

Informed Consent Statement: Not applicable. 
Data Availability Statement: Data are contained within the article.

Conflicts of Interest: The authors declare no conflict of interest.

\section{References}

1. Sharifi-Rad, M.; Anil Kumar, N.V.; Zucca, P.; Varoni, E.M.; Dini, L.; Panzarini, E.; Rajkovic, J.; Tsouh Fokou, P.V.; Azzini, E.; Peluso, I.; et al. Lifestyle, oxidative stress, and antioxidants: Back and forth in the pathophysiology of chronic diseases. Front. Physiol. 2020, 11, 694. [CrossRef] [PubMed]

2. Rahman, K. Studies on free radicals, antioxidants, and co-factors. Clin. Interv. Aging 2007, 2, 219-236. [PubMed]

3. Lobo, V.; Patil, A.; Phatak, A.; Chandra, N. Free radicals, antioxidants and functional foods: Impact on human health. Pharmacogn. Rev. 2010, 4, 118-126. [CrossRef] [PubMed]

4. Ndhlala, A.R.; Moyo, M.; Staden, J.V. Natural antioxidants: Fascinating or mythical biomolecules? Molecules 2010, 15, 6905-6930. [CrossRef] [PubMed]

5. Shahidi, F.; Ambigaipalan, P. Phenolics and polyphenolics in foods, beverages and spices: Antioxidant activity and health effects-A review. J. Funct. Food. 2015, 18, 820-897.

6. Maqsood, S.; Benjakul, S.; Abushelaibi, A.; Alam, A. Phenolic compounds and plant phenolic extracts as natural antioxidants in prevention of lipid oxidation in seafood: A detailed review. Compr. Rev. Food. Sci. Food Saf. 2014, 13, 1125-1140. [CrossRef]

7. Pan, H.Z.; Zhang, L.; Guo, M.Y.; Sui, H.; Li, H.; Wu, W.H.; Qu, N.Q.; Liang, M.H.; Chang, D. The oxidative stress status in diabetes mellitus and diabetic nephropathy. Acta Diabetol. 2010, 47, 71-76. [CrossRef]

8. Elmarakby, A.A.; Sullivan, J.C. Relationship between oxidative stress and inflammatory cytokines in diabetic nephropathy. Cardiovasc. Ther. 2012, 30, 49-59. [CrossRef]

9. Yang, H.; Jin, X.; Wai, C.; Lam, K.; Yan, S.K. Oxidative stress and diabetes mellitus. Clin. Chem. Lab. Med. 2011, 49, 1773-1782. [CrossRef]

10. Chen, J.G.; Wu, S.F.; Zhang, Q.F.; Yin, Z.P.; Zhang, L. $\alpha$-Glucosidase inhibitory effect of anthocyanins from Cinnamomum camphora fruit: Inhibition kinetics and mechanistic insights through in vitro and in silico studies. Int. J. Biol. Macromol. 2020, 143, 696-703. [CrossRef]

11. Shai, L.J.; Masoko, P.; Mokgotho, M.P.; Magano, S.R.; Mogale, A.M.; Boaduo, N.; Eloff, J.N. Yeast alpha glucosidase inhibitory and antioxidant activities of six medicinal plants collected in Phalaborwa, South Africa. S. Afr. J. Bot. 2010, 76, 465-470. [CrossRef]

12. Wu, J.Q.; Peng, W.; Qin, R.X.; Zhou, H. Crataegus pinnatifida: Chemical constituents, pharmacology, and potential applications. Molecules 2014, 19, 1685-1712. [CrossRef] [PubMed]

13. Daniele, C.; Mazzanti, G.; Pittler, M.H.; Ernst, E. Adverse-event profile of Crataegus spp. Drug Saf. 2006, 29, 523-535. [CrossRef] [PubMed]

14. Chang, Q.; Zuo, Z.; Harrison, F.; Chow, M.S.S. Hawthorn. J. Clin. Pharmacol. 2002, 42, 605-612. [CrossRef] [PubMed]

15. Jurikova, T.; Sochor, J.; Rop, O.; Mlcek, J.; Balla, S.; Szekeres, L.; Adam, V.; Kizek, R. Polyphenolic profile and biological activity of Chinese hawthorn (Crataegus pinnatifida Bunge) fruits. Molecules 2012, 17, 14490-14509. [CrossRef] [PubMed]

16. Dehghani, S.; Mehri, S.; Hosseinzadeh, H. The effects of Crataegus pinnatifida (Chinese hawthorn) on metabolic syndrome: A review. Iran J. Basic Med. Sci. 2019, 22, 460-468.

17. Kao, E.S.; Wang, C.J.; Lin, W.L.; Yin, Y.F.; Wang, C.P.; Tseng, T.H. Anti-inflammatory potential of flavonoid contents from dried fruit of Crataegus pinnatifida in vitro and in vivo. J. Agric. Food Chem. 2005, 53, 430-436. [CrossRef]

18. Zhang, J.Y.; Liang, R.X.; Wang, L.; Yan, R.Y.; Hou, R.; Gao, S.R.; Yang, B. Effects of an aqueous extract of Crataegus pinnatifida Bge var. major N.E.Br. fruit on experimental atherosclerosis in rats. J. Ethnopharmacol. 2013, 148, 563-569.

19. Djordjevic, T.M.; Šiler-Marinkovic, S.S.; Dimitrijevic-Brankovic, S.I. Antioxidant activity and total phenolic content in some cereals and legumes. Int. J. Food Prop. 2011, 14, 175-184. [CrossRef]

20. Do, Q.D.; Angkawijaya, A.E.; Tran-Nguyen, P.L. Effect of extraction solvent on total phenol content, total flavonoid content, and antioxidant activity of Limnophila aromatica. J. Food Drug Anal. 2014, 22, 296-302. [CrossRef]

21. Brand-Williams, W.; Cuvelier, M.E.; Berse, C. Use of a free radical method to evaluate antioxidant activity. LWT-Food Sci. Technol. 1995, 28, 25-30. [CrossRef]

22. Re, R.; Pellegrini, N.; Proteggente, A.; Pannala, A.; Yang, M.; Rice-Evans, C. Antioxidant activity applying an improved ABTS radical cation decolorization assay. Free Radic. Biol. Med. 1999, 26, 1231-1237. [CrossRef]

23. Siddhuraju, P.; Becker, K. The antioxidant and free radical scavenging activities of processed cowpea (Vigna Unguiculata (L.) Walp.) seed extracts. Food Chem. 2007, 101, 10-19. [CrossRef]

24. Mathew, S.; Abraham, T.E. Studies on the antioxidant activities of cinnamon (Cinnamomum verum) bark extracts, through various in vitro models. Food Chem. 2006, 94, 520-528. [CrossRef]

25. Thaiponga, K.; Boonprakoba, U.; Crosbyb, K.; Cisneros-Zevallosc, L.; Byrnec, D.H. Comparison of ABTS, DPPH, FRAP, and ORAC assays for estimating antioxidant activity from guava fruit extracts. J. Food Compos. Anal. 2006, 19, 669-675. [CrossRef]

26. Hou, W.; Li, Y.F.; Zhang, Q.; Wei, X.; Peng, A.; Chen, L.J.; Wei, Y. Triterpene acids isolated from Lagerstroemia speciosa leaves as $\alpha$-glucosidase inhibitors. Phytother. Res. 2009, 23, 614-618. [CrossRef] [PubMed]

27. Wang, W.; Wu, N.; Zu, Y.G.; Fu, Y.J. Antioxidative activity of Rosmarinus officinalis L. essential oil compared to its main components. Food Chem. 2008, 108, 1019-1022. [PubMed] 
28. Floegel, A.; Kim, D.O.; Chung, S.J.; Koo, S.I.; Chun, O.K. Comparison of ABTS/DPPH assays to measure antioxidant capacity in popular antioxidant-rich US foods. J. Food Compos. Anal. 2011, 24, 1043-1048. [CrossRef]

29. Gülçin, İ.; Şat, İ.G.; Beydemir, Ş.; Elmastaş, M.; Küfrevioğlu, Ö.İ. Comparison of antioxidant activity of clove (Eugenia caryophylata Thunb) buds and lavender (Lavandula stoechas L.). Food Chem. 2004, 87, 393-400. [CrossRef]

30. Joubert, E.; Winterton, P.; Britz, T.J.; Gelderblom, W.C.A. Antioxidant and pro-oxidant activities of aqueous extracts and crude polyphenolic fractions of rooibos (Aspalathus linearis). J. Agric. Food Chem. 2005, 53, 10260-10267. [CrossRef]

31. Ou, B.; Huang, D.; Hampsch-Woodill, M.; Flanagan, J.A.; Deemer, E.K. Analysis of antioxidant activities of common vegetables employing oxygen radical absorbance capacity (ORAC) and ferric reducing antioxidant power (FRAP) assays: A comparative study. J. Agric. Food Chem. 2002, 50, 3122-3128. [CrossRef]

32. Kumar, S.; Narwal, S.; Kumar, V.; Prakash, O. $\alpha$-Glucosidase inhibitors from plants: A natural approach to treat diabetes. Pharmacogn. Rev. 2011, 5, 19-29. [CrossRef] [PubMed]

33. Hossain, U.; Das, A.K.; Ghosh, S.; Sil, P.C. An overview on the role of bioactive $\alpha$-glucosidase inhibitors in ameliorating diabetic complications. Food Chem. Toxicol. 2020, 145, 111738. [CrossRef] [PubMed]

34. Tagami, T.; Yamashita, K.; Okuyama, M.; Mori, H.; Yao, M.; Kimura, A. Molecular basis for the recognition of long-chain substrates by plant $\alpha$-glucosidase. J. Biol. Chem. 2013, 288, 19296-19303. [CrossRef] [PubMed] 